Brit. J. industr. Med., 1953, 10, 114.

\title{
THE EXPECTED FREQUENCY OF BLADDER TUMOUR IN WORKS POPULATIONS
}

\author{
BY \\ R. A. M. CASE \\ From the Chester Beatty Research Institute, the Institute of Cancer Research, University of London
}

(RECEIVED FOR PUBLICATION NOVEMBER 19, 1952)

It has long been recognized that certain occupations, such as the manufacture or use of some dyestuff intermediates, have caused an increase in the frequency of either papilloma or carcinoma of the bladder. It is unnecessary here to make detailed references to papers on this topic, since an extensive review was written by Goldblatt in 1947.

There is little or no certainty, however, as to how far such an occupational risk affects other industries or occupations, and before an occupational risk of this sort can be recognized it is necessary to show that more cases are occurring amongst men employed in a particular environment than occur amongst men not so employed. This comparison makes it necessary to have an estimate of the expected frequency of the disorder that would occur among the same men if no environmental risk were affecting them.

Unfortunately, sickness records for England and Wales are not sufficiently complete to enable an estimate to be made of the frequency with which papilloma or carcinoma of the bladder occurs in living patients, but it is possible to form a reasonably precise estimate of the number of death certificates which mention papilloma or carcinoma of the bladder for males in England and Wales. Such an estimate will give the frequency of death certificates mentioning tumour of the bladder at the average rate for males in England and Wales, a figure not quite the same as the death rate for the disorder, since some of the deaths are assigned to other causes, although the certificate also mentions bladder tumour. For the present purpose the estimate of certificates mentioning tumour of the bladder is more appropriate than the death rate.

It is also possible to obtain a copy of the death certificate of a deceased person, so that if death records are kept by a firm the number of death certificates mentioning tumour of the bladder that actually occur can be found, and a comparison of the number expected and the number found can be made. Collecting the information about the actual number of death certificates with mention of tumour of the bladder may present some difficulty. For the future, this could partly be solved by the employing firm keeping death records, but this would not give a complete record, since it would not be practicable to complete such records for all men who had left the particular employment.

By arrangement with the Registrar General an alphabetical register of all deaths in England and Wales of males whose death certificates contained mention of bladder tumour is at present being maintained at the Chester Beatty Research Institute. This covers the years $1936-50$, but will be extended from year to year as information becomes available. With adequate safeguards against misuse of the information contained in the register, it would be possible to arrange for lists of men on the nominal roll to be checked against this register with a view to full death certificates being obtained from the General Register Office where necessary. To save labour such lists should be the nominal roll used to form the estimate with the names of men known to be alive removed from it. This procedure would also ensure that any desired degree of industrial reticence could be preserved. Should a demand become apparent, the register could also be extended to cover the period 1921-35.

It thus becomes possible for medical officers or other responsible persons having access to works records to investigate whether or not there is any reason to believe that a particular industry, occupation, or process gives rise to tumours of the urinary bladder. It is of course necessary that the works records should be sufficiently complete to enable this to be done.

The purpose of this paper is to describe how the 
苟

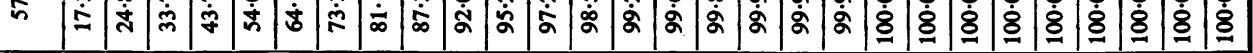

它

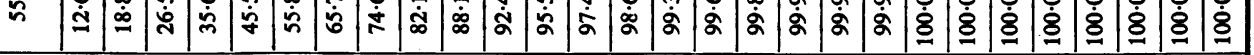

¿

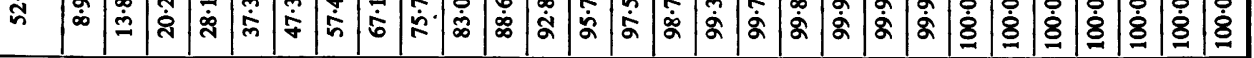

官 ڤ ம)

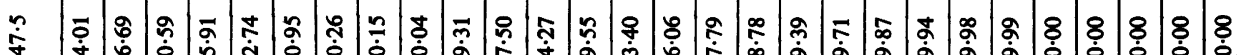
-

过

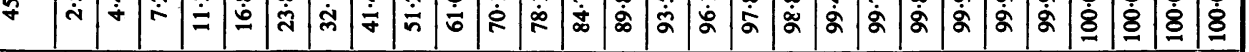

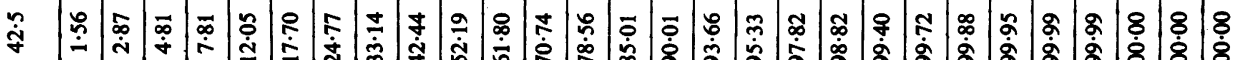

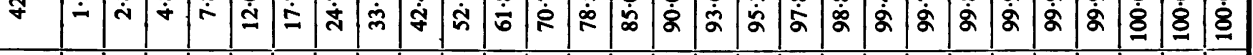

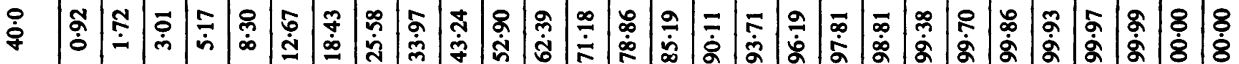

$n \log (\theta)$

夜

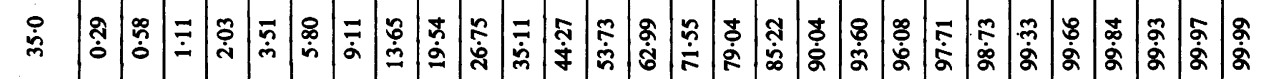

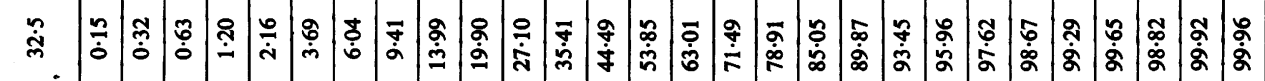

它

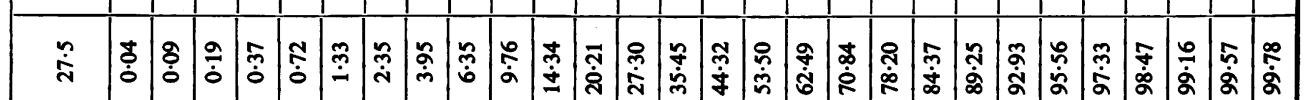

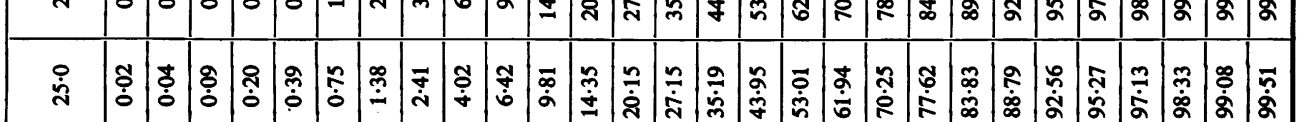

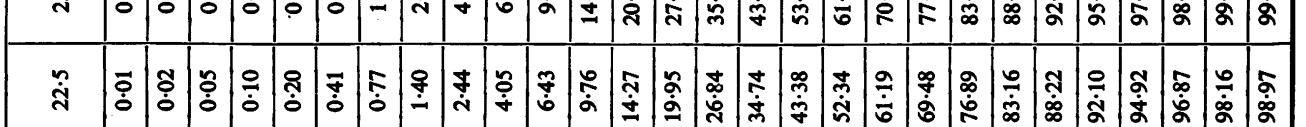

त 0 O

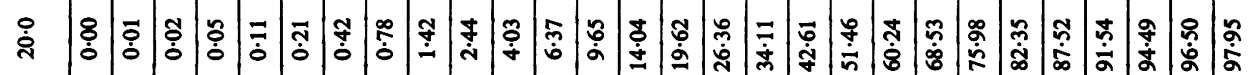

兵

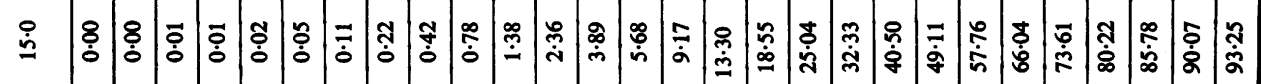

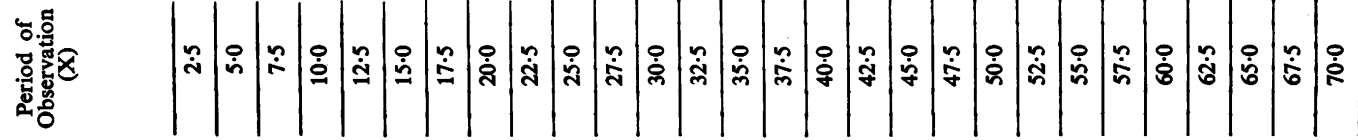


estimate of the number of bladder tumours at the mean rate for males in England and Wales (referred to as the expected number) can be made. The theoretical basis of the calculation is complex, but an understanding of the full details of this basis is unnecessary for forming the estimate, and they have therefore been described elsewhere (Case, 1953).

The underlying principles of the method, which is a form of cohort analysis, are that the disease becomes progressively more common with increasing age of the individual until 80 is attained, and that the death rate from this cause at any given age has increased in a more or less regular manner between 1920 and the present day. In addition, death rates from all causes have tended to decrease at any given age during the same time.

An extensive study (Case, 1953) of the death rates from bladder tumour for the 30 years $1921-50$ has made it possible to construct tables of factors (Tables A and B) which will allow these changes to be assessed with reasonable accuracy when considering a group (cohort) of men originally in a stated age group $(Z)$ who enter a specified environment between certain dates and who are then observed for $\mathrm{X}$ years to the date of assessment. The men are considered as having acquired bladder tumours at the rate that would have obtained if the

TABLE C

HIGHEST ESTIMATED VALUE PERMITTING THE ASSUMPTION THAT THE NUMBER OF DEATH CERTIFICATES INDICATES AN ENVIRONMENTAL RISK

\begin{tabular}{|c|c|c|}
\hline $\begin{array}{l}\text { No. of Bladder } \\
\text { Tumour Death } \\
\text { Certificates } \\
\text { Actually Found } \\
\text { (1) }\end{array}$ & $\begin{array}{c}\text { Highest Estimated } \\
\text { Value Making } \\
\text { Nos. in Col. } 1 \\
\text { Suspect } \\
\text { (2) }\end{array}$ & $\begin{array}{c}\text { Highest Estimated } \\
\text { Value Making } \\
\text { Nos. in Col. 1 } \\
\text { Excessive } \\
\text { (3) }\end{array}$ \\
\hline 1 & 0.052 & 0.020 \\
\hline 2 & $0 \cdot 356$ & $0 \cdot 215$ \\
\hline 3 & $0 \cdot 818$ & 0.567 \\
\hline 4 & 1.367 & 1.016 \\
\hline 5 & 1.970 & $1 \cdot 530$ \\
\hline 6 & $2 \cdot 613$ & 2.089 \\
\hline 7 & $3 \cdot 285$ & 2.684 \\
\hline 8 & 3.981 & $3 \cdot 307$ \\
\hline 9 & 4.695 & 3.953 \\
\hline 10 & $5 \cdot 426$ & $4 \cdot 619$ \\
\hline 11 & $6 \cdot 169$ & $5 \cdot 300$ \\
\hline 12 & 6.920 & $5 \cdot 996$ \\
\hline 13 & $7 \cdot 690$ & $6 \cdot 705$ \\
\hline 14 & 8.854 & $7 \cdot 424$ \\
\hline 15 & $9 \cdot 247$ & $8 \cdot 153$ \\
\hline
\end{tabular}

whole of the $\mathrm{X}$ years had the risks at each age current for the date $w$, which is the mid-point between the date of starting and the date of assessment.

The Table A factors represent the percentage reached by the date of assessment of the final incidence of death from bladder tumour that would occur in a cohort of men originally aged $\mathbf{Z}$ who were observed until death from any cause had wiped out the cohort. The Table B factors show what this final incidence would be (as a percentage of the number of men in the original cohort) for men starting at different ages and different dates.

Table $\mathrm{C}$ gives the highest estimated value that makes it possible to assume an environmental risk.

\section{Methods}

Works Records. - It is necessary to search the works records and find what men have worked in the environment under consideration, the date at which they entered that environment, and their age when they did so. It is desirable to define a lower limit for time of employment by the firm (say six months) since people who are only employed for a week or so tend to be migrants and it would be difficult to trace their death certificates when they died. Subsequent withdrawal from the environment by change of occupation or retirement does not affect the method except insofar as it makes the proof of identity of the man and a possible death certificate more tedious. Having compiled such a list of men, which will be described as a nominal roll, it should be set out in the following manner.

The men should be grouped according to the date at which they started work in the environment under consideration; this will be called the date of entry. The dates of entry should be arranged in convenient groups, preferably of five years each, and the date of entry used for the calculation is the date of the midpoint of that group.

The men in each date of entry group should be divided further according to how old they were at that date. This age is termed the age at entry, and these ages should be arranged in groups of 10 , or, preferably, five years, and the ages at entry used for the calculation are the ages at the mid-points of these groups. An example of this process is shown in Table 1. The age groups should be chosen so that the mid-points lie on a figure ending in $2 \cdot 5,5 \cdot 0,7 \cdot 5$, or 0.0

It is now necessary to decide at what date the final assessment is to be made. For example, a process has records extending from 1920 to 1950 , and death records have been searched up to January 1,1950 . The final assessment is therefore made at 1950 , and this is called the end of the period of observation. This should be chosen in relation to the age of entry groups so that the $X$ values lie on figures ending in $2 \cdot 5,5 \cdot 0,7 \cdot 5$, or 0.0 .

Now for each age of entry group there is a mid-point, which is called $Z$, and for each date of entry group there 


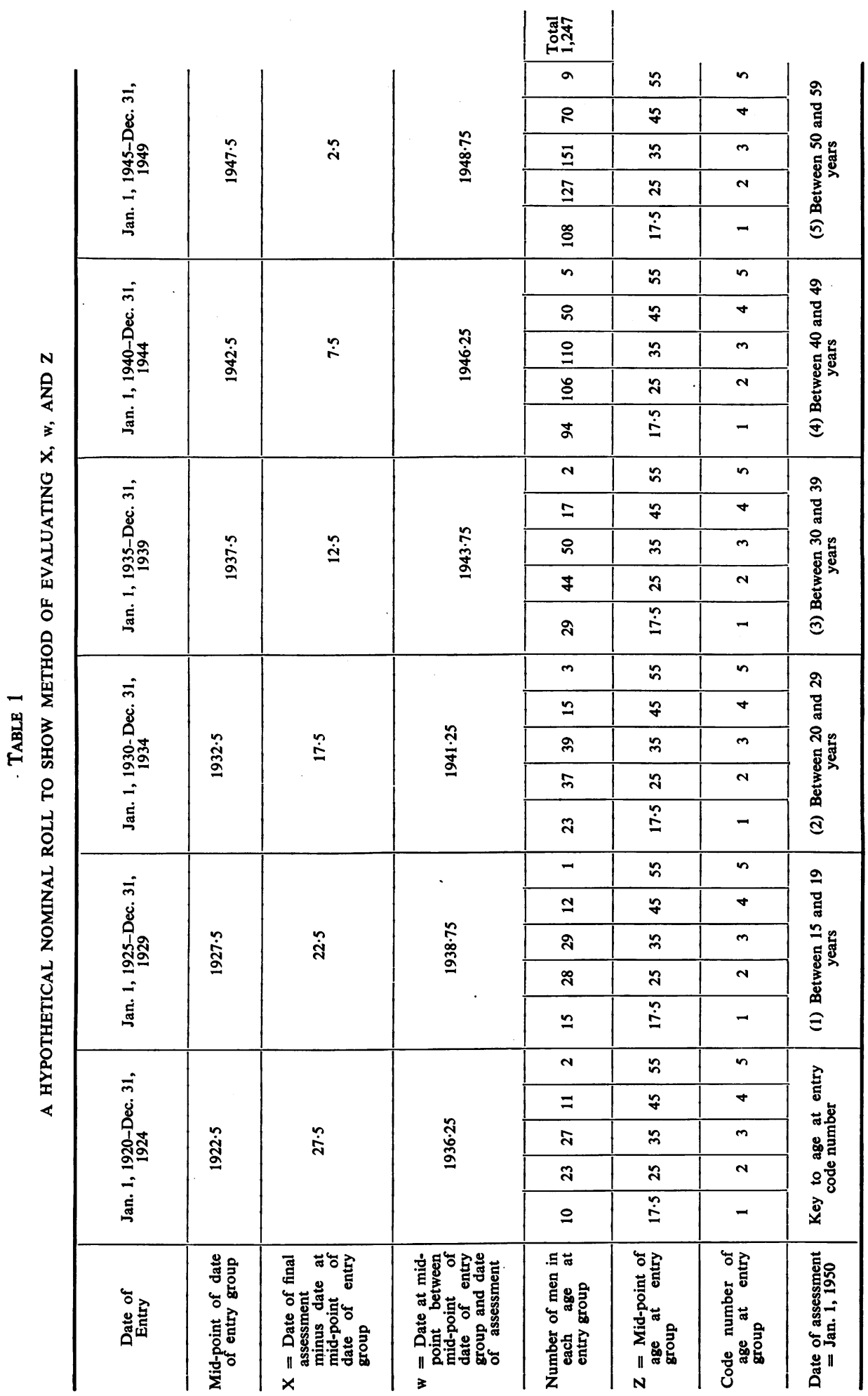

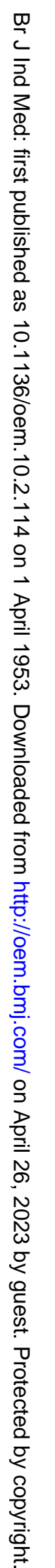


is an interval of time from the date of the mid-point of that group until the end of the period of observation which is called $X$. There is also at the mid-point of the period of observation a date which is called $w$.

The values of $Z, X$, and $w$ are easily found from Table 1 for each group of men. (It must be clearly understood that the Table 1 shown here is an example constructed from a hypothetical population. In practice Table 1 must be constructed for the population being considered, and the values found from this.) Tables A, B, and C are constants and require no further calculation.

All that is now necessary is to multiply the number of men in each small division of Table 1 by the factor from Table $A$ and then by the factor from Table B, the appropriate factors being identified by the value of $X$, $Z$, and $w$ for that particular subdivision, add up all these products, and divide by 10,000 . This is the estimate of the expected number of death certificates. Table 2 shows the workings of this calculation for the hypothetical population set out in Table 1 . The selection of the mid-points of the age of entry groups and the values for $\mathrm{X}$ described above ensures that no interpolation is necessary in Table $\mathrm{A}$, where the differences between successive entries are not linear. The $w$ values may necessitate interpolation in Table $\mathrm{B}$, but here the differ- ences are linear and the necessary figures are easily found by inspection.

It is next necessary to compare the number of death certificates actually found from this body of men with this estimate. Obviously, the number actually found can only be a whole number, though the estimate may be a fraction. Table $\mathrm{C}$ shows the highest value of the estimate permitted for a number of certificates between 1 and 15 actually found if one is to say that there are more found than would be expected by chance, i.e., if one is to say that there is an environmental risk.

This table gives two figures for the highest estimate of deaths from bladder tumour expected in a particular population. If the calculation gives a figure higher than in column 2 there is no ground for suspicion; if it gives a figure falling between the numbers in columns 2 and 3 the chance of having obtained so large a difference between expectation and observation from random errors is less than 1 in 20 and it may be suspected that an environmental risk is operating; if it gives a figure falling below that in the third column this chance is less than 1 in 50 and it may safely be assumed that such a risk is operating.

\section{Summary}

A method is described whereby works medical officers or other interested persons with access to

TABLE 2

HYPOTHETICAL POPULATION SHOWN IN TABLE 1 WORKED OUT AS A NUMERICAL EXAMPLE

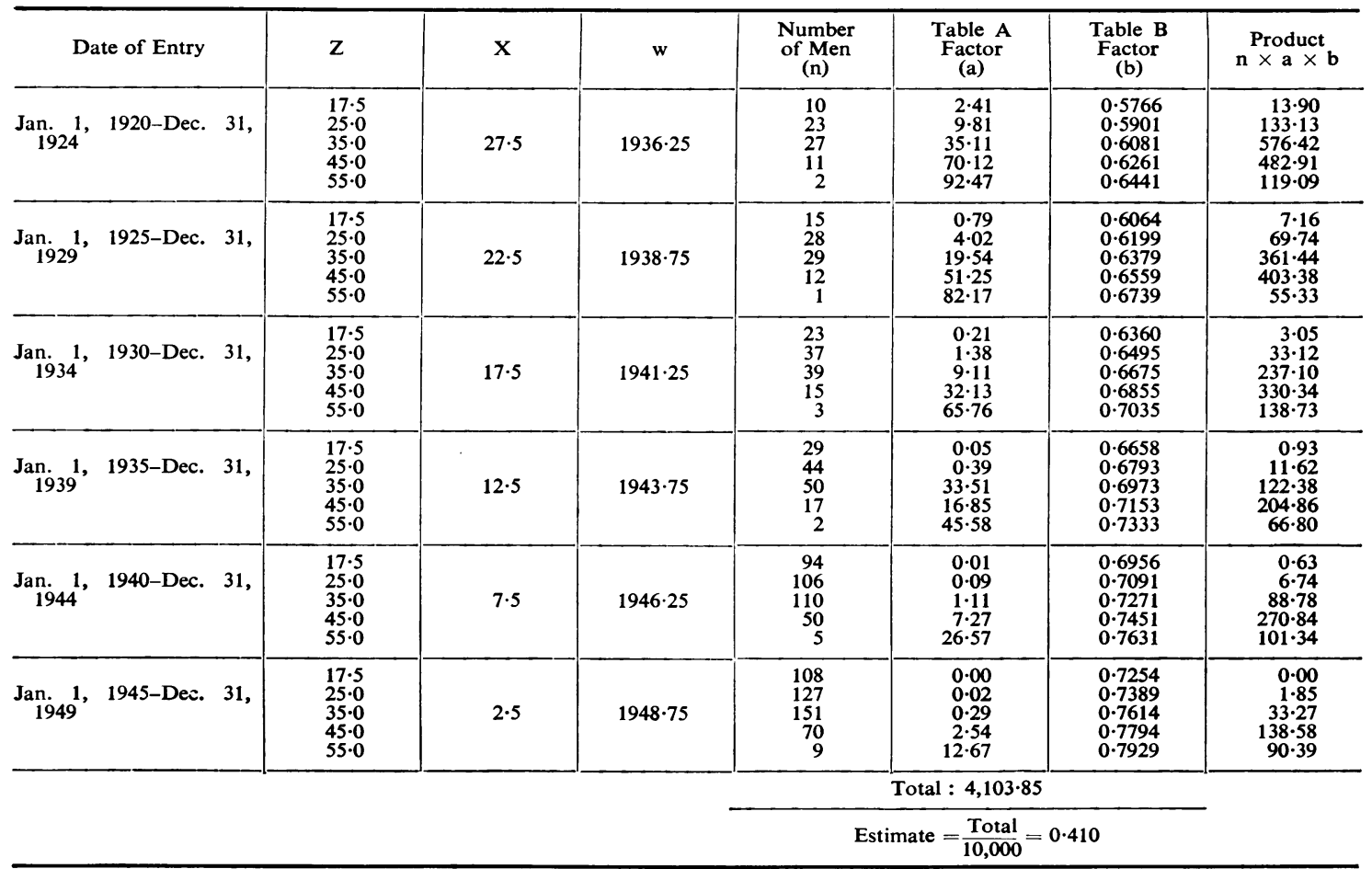


works records can obtain an idea of whether an environmental risk of bladder tumour formation exists in industries, occupations, or processes in which they are interested, assuming that the works records show the name of the employee, his age or date of birth, and the date at which he started work in the environment to be considered. It is also necessary to find the number of deaths from bladder tumour which have in fact occurred.

The method is applicable to males in England and Wales, and is valid for employment between 1921 and 1950, but probably no great error will be introduced by extending these limits by about a decade either way.

No expert statistical knowledge is required for using the method.

The alphabetical index has been constructed by Miss Margery E. Hosker and Miss Joan T. Pearson.

The work has been carried out under the auspices of the Association of British Chemical Manufacturers.

\section{REFERENCES}

Case, R. A. M. (1953) Brit. J.prev. soc. Med., 7, 14. Goldblatt, M. W. (1947). Brit. med. Bull., 4, 405.' 